\title{
The Influence of Aggressiveness on Rape-Myth Acceptance among University Students
}

Manpal Singh Bhogal and Stacey Corbett

'Department of Psychology, Coventry University, UK

The detrimental effects of rape are well established. In order to support victims of rape in reporting sexual assault, the factors which predict rape myths need to be investigated. Aggression has been linked to sexual violence, but little is known about the role of aggressive behaviour in rape-myth acceptance. The present study aimed to investigate whether rape myths could be predicted by verbal aggression, physical aggression, hostility, anger or sex in a sample of 121 participants. A regression analysis found that an individual's sex and self-reported physical aggression significantly predicted rape-myth acceptance.

Keywords: aggression; rape attitudes; rape-myth acceptance; sex.

\footnotetext{
${ }^{1}$ Correspondence: Manpal Singh Bhogal, Department of Psychology, Coventry University, Priory Street, Coventry, CV1 5FB, UK. Tel.: 02477 654623. Email: ab6430@coventry.ac.uk
} 


\section{Introduction}

Rape is a widespread phenomenon occur- ring internationally and across cultures (Grubb \& Turner, 2012). Approximately 85,000 women are raped on average in England and Wales every year, with over 400,000 women being sexually assaulted (Office for National Statistics Bulletin, 2013). This demonstrates that rape is a pervasive issue in modern society (Suarez \& Gadalla, 2010). Alarming as these figures are, it is surprising that rape and sexual assaults are the most under-reported crimes in the United Kingdom (Grubb \& Turner, 2012), rendering the above figures an inaccurate representation of the issue. This may be due to the stigmas attached to victims of rape, attitudes towards the crime itself and the existence of rape myths which can affect the way in which society perceives rape. The negative consequences of rape have led to empirical research into its causes and consequences (Kolivas \& Gross, 2007).

\section{Rape Myths}

Individuals are more likely to commit a sexual offence if they endorse rape myths (Bohner et al., 1998; Koss \& Dinero, 1988). In addition, convicted and self-confessed rapists display higher levels of rape-myth acceptance compared to non-rapists (Field, 1978; Koralewski \& Conger, 1992). These myths are defined as 'attitudes and beliefs that are generally false but are widely and persistently held, and that serve to deny and justify male sexual aggression against women' (Lonsway \& Fitzgerald, 1994, p. 134). Evidence suggests that those who endorse sexually aggressive behaviours are likely to respond less empathically, 
be less supportive of rape victims and engage in victim-blaming behaviour which causes victims to feel embarrassed about their ordeal and thus not report the crime committed against them (Flood \& Pease, 2009; Stahl, Eek, \& Kazemi, 2010). Some victims may believe they are to blame and may not have a support system if they report victimisation (Flood \& Pease, 2009). Dispelling rape myths and their accompanying attitudes and beliefs may increase empathy towards victims, which may in turn provide victims with the confidence to report rape and sexual assault. Therefore, it is important to investigate the predictors of rape-myth acceptance.

Males report higher rape-myth acceptance compared to females (for a meta-analysis, see Suarez \& Gadalla, 2010). Because rape is a sexual offence it is often presumed that motivations of rape are purely sexual, implying that the offender is sexually frustrated (Groth, 1979). However, studies suggest that most rapists have sexual partners and are sexually active at the time of their offence (Scully, 1990). Rape satisfies the non-sexual needs of the offender and is a way of expressing and maintaining power, control and dominance (Ellis 1989; Groth, 1979). In addition, some rapists are unable to have an erection or ejaculate during rape (Groth, 1979), which further supports this proposition. A common myth is that women provoke rape by the way in which they dress and/or act (Reddington \& Kreisel, 2005). This myth implies that the victim is to blame for the crime and assumes that those who dress provocatively are 'looking for sex'. The above misconception is relevant because it challenges this rape myth and its victim-blaming mentality. 
A common theme in rape myths is that they minimise the victim's injury by blaming the victim for the occurrence of the act (Carmody \& Washington, 2001; Schwartz \& Leggett, 1999). The attribution of blame in rape cases include the victim's respectability (Luginbuhl \& Mullin, 1981), perceived physical attractiveness (Tieger, 1981), provocativeness (Scroggs, 1976), previous sexual activity (L'Armand \& Pepitone, 1982), amount of resistance to the attack (Van Wie, Gross, \& Marx, 1995), intoxication levels (Richardson \& Campbell, 1982) and manner of dress at the time of the attack (Edmonds \& Cahoon, 1986). The psychological consequences after being raped include depression, revenge fantasies, post-traumatic stress disorder, sexual dysfunction and confusion about sexual identity (Walker, Archer, \& Davies, 2005). This demonstrates the need to investigate the factors which can challenge rape myths and support victims of rape.

\section{The Role of Aggression}

Previous research has investigated the impact that violent and aggressive behaviour has on attitudes towards rape. Evidence suggests that those who engage in sexually aggressive behaviours report high levels of general aggressiveness (Gidycz, Warkentin, \& Orchowski, 2007; Lalumiere, Harris, Quinsey, \& Rice, 2005; Wilson, Mouilso, Gentile, Calhoun, \& Zeichner, 2015). As a result, aggressiveness may influence rape-myth acceptance.

Beck, Boys, Rose, and Beck (2012) investigated the influence of the level of violence, aggressive behaviour and sexual objectification shown towards women in videogames. The results indicated that male participants who play such games report a significant increase 
in rape-myth acceptance. Nunes, Hermann, and Ratcliffe (2013) investigated the relationship between sexual aggression and implicit/explicit attitudes towards rape. Their results showed significant group differences between sexually aggressive and nonaggressive participants. The most sexually aggressive participants showed more positive implicit and explicit attitudes towards rape. There appears to be a lack of research into the role of aggressive tendencies and attitudes towards rape-myth acceptance.

\section{The Role of Sex}

Sex and rape-myth acceptance has been researched extensively. White and Kurpius (1999) found that men have higher levels of rape-myth acceptance compared to women. Research has shown that males are most likely to commit a sexual assault during their time at university, which is a rationale for conducting such a study using a university sample (Holcomb, Holcomb, Sondag, \& Williams, 1988). In addition, sexual assault rates for women studying at university are three times greater than women in the general public (Koss \& Gidycz, 1985). This risk may be exacerbated by factors such as alcohol use, greater sexual expectation and the perceived availability of attractive partners (Burgess, 2007). In Malamuth (1981), 35\% of the male university students surveyed disclosed that there was a chance they would commit a sexual assault if they were sure they would not be caught or punished.

\section{The Current Study}

This study aimed to investigate rape-myth acceptance among university students. This 
research aimed to determine if sex, verbal aggression, physical aggression, hostility and anger significantly predict rape-myth acceptance. The study had two hypotheses:

Hypothesis 1: Sex, physical aggression, verbal aggression, anger and hostility significantly influence rape-myth acceptance.

Hypothesis 2: The male participants would exhibit significantly higher levels of rape- myth acceptance than the female participants.

\section{Method}

\section{Participants and Design}

A total of 121 undergraduate students from Coventry University took part. The sample included 56 males and 65 females (mean age D 19 years, SD D 0.98). Psychology students were awarded research credits as part of the department's research participation scheme. Of the sample, 30\% was Black British, 37\% was White British, 27\% was Asian British and $5 \%$ did not disclose their ethnicity. This study adopted a correlational design. The predictor variables were physical aggression, verbal aggression, hostility, anger, and sex. The outcome variable was rape-myth acceptance.

\section{Materials and Procedure}

Participants completed the Illinois Rape Myth Acceptance Scale (Payne, Lonsway, \& Fitzgerald, 1999) and Buss and Perry's (1992) aggression scale. The Illinois Rape Myth Acceptance Scale includes four sub- scales. Participants were asked to rate 22 statements 
on a 1 to 5 Likert scale. This scale has been found to be reliable and robust (Payne et al., 1999). Previous studies that have also used this measure have found that it has sufficient internal consistency, reliability and construct validity (see Baugher, Elhai, Monroe, \& Gray, 2010; Paul, Gray, Elhai, \& Davis, 2009). The scale was found to be reliable in this study (a D .73).

The Buss Perry scale used to measure aggression. Participants were asked to rate 29 statements on a 1 to 7 Likert scale. This scale identifies levels of physical aggression, verbal aggression, anger and hostility. The scale has been found to have moderate to high internal consistency and the four aggression scales were positively related to other measures of aggression (Harris, 1997). This scale has good internal consistency, discriminant validity, convergent validity and test-retest reliability (Valdivia-Peralta, Fonseca-Pedrero, Gonzalez-Bravo, \& Lemos-Gir aldez, 2014). This study was approved by the host university's behavioural ethics committee. Reliability was found to be good for each subscale in the present study: physical aggression $(a=.72)$, verbal aggression $(a=.78)$ anger $(\mathrm{a}=.80)$ and hostility $(\mathrm{a}=.70)$.

\section{Results}

Hypothesis 1: Sex, physical aggression, verbal aggression, anger and hostility significantly influence rape-myth acceptance.

Multiple regression was conducted to measure the impact of sex (male/female), physical aggression, verbal aggression, anger and hostility on rape-myth acceptance. 
Table 1. Correlation coefficients between all variables including descriptive statistics.

\begin{tabular}{llll}
\hline 1.RMA & 2.PA & 3.VA & 4. Anger \\
$(M=45.9, S D=$ & $(M=29, S D=\quad(M=18.89, \quad(M=22.1, S D=5.51)(M=27.1, S D=10.3)$ \\
$14.35)$ & $7.53)$ & $S D=5.94)$
\end{tabular}

\section{RMA}

2. PA $r=.30 * *$

3. VA r=.11 r=-.25* -----

4. Anger $\mathrm{r}=.10 \quad \mathrm{r}=.19 \quad \mathbf{2 1} \quad$

5. Hostility $\mathrm{r}=.16 \quad \mathrm{r}=.29 * \quad \mathrm{r}=.21 * \quad \mathrm{r}=.24 *$

$* p<.05$

$* * p<.01$

Preliminary analyses were conducted to ensure that there was no violation of the assumptions of normality, linearity, multicollinearity and homoscedasticity. Variables were converted to z-scores in order to provide standardised regression values (Table 2). The total variance explained by the model as a whole was $16 \%, F(5,115) \mathrm{D} 4.36, p<.001$. 
Table 2. Summary of standardized regression variables.

\section{5\% CI (Standardized)}

\begin{tabular}{lllll}
\hline Predictor variables & $\boldsymbol{\beta}$ & $\boldsymbol{p}$ & Lower Bound & Upper Bound \\
Sex & $-.26^{*}$ & $.04 * *$ & -.87 & -.72 \\
Physical Aggression & $.23 *$ & $.03 *$ & .02 & .43 \\
Verbal Aggression & .002 & .98 & -.19 & .19 \\
Anger & -.03 & .80 & -.25 & .20 \\
Hostility & .08 & .47 & -.13 & .28 \\
\hline \multirow{2}{*}{$* p<.05$} & $* * p<.01$ & & &
\end{tabular}

Hypothesis 2: The male participants would exhibit significantly higher levels of rape- myth acceptance than the female participants.

A one-way between-group analysis of variance (ANOVA) was conducted to explore sex differences in rape-myth acceptance, physical aggression, verbal aggression, anger and hostility. There were significant sex differences in rape-myth acceptance, $F(1,119)=$ $12.95, \mathrm{p}<.001, \mathrm{n} 2.098$, with males displaying higher rape-myth acceptance $(\mathrm{M}=50.75$, $\mathrm{SD}=15.05)$ than females $(\mathrm{M}=41.78, \mathrm{SD}=12.39)$. A sex difference was also found in physical aggression, $F(1,119)=4.99, \mathrm{p}<.05, \mathrm{n} 2.04$, with males displaying higher levels of self-reported physical aggression $(M=30.58, S D=6.68)$ than females $(M=27.56, S D$ $=7.98)$. 


\section{Discussion}

The aims of the current study were to explore rape-myth acceptance amongst university students and to investigate the influence of sex, physical aggression, verbal aggression, anger and hostility on rape-myth acceptance. Sex and physical aggression significantly influenced rape-myth acceptance. Therefore, Hypothesis 1 was partially supported. Hypothesis 2 was fully supported, as males held higher rates of rape-myth acceptance than females.

Males were found to report significantly higher rape-myth acceptance and higher levels of physical aggression compared to females. Furthermore, physical aggression and sex were the only significant predictors of rape-myth acceptance. This finding is consistent with previous research investigating the effect of sex on rape myths (Suarez \& Gadalla, 2010; White \& Kurpius, 1999).

An explanation for the sex difference found in rape-myth acceptance and physical aggression may relate to socialisation and exposure to physically aggressive content towards women in the media. For example, research suggests that playing videogames that show violence against women increases rape myths among male participants (Beck et al., 2012; Nunes et al., 2013). Exposure to violent, aggressive stimuli directed towards women may increase rape-myth acceptance in men. The same relationship has been echoed in research conducted by Nunes et al. (2013), who found that the most aggressive participants had more positive attitudes towards rape. Ellis (1989) argued that individuals are taught 
gender-appropriate behaviour through a socialisation process, built on social learning theory. This occurs through frequent and repeated displays of violence and aggressiveness towards women in the mass media, society and family environment. This exposure leads to tolerance which causes violent acts against women to be undermined and may also relate to the underreporting of rape by victims (Ellis, 1989).

Pornography may also partially explain our finding. Although this paper does not explore pornographic use, it may be that men report higher physical aggression and acceptance of rape myths due to the manner in which women are portrayed in pornography (Wright \& Randall, 2012), such as pornography with a bondage and discipline, dominance and submission, sadism and masochism (BDSM) theme. Violent pornography typically depicts men displaying sexual, physical and verbal aggression towards women (Fisher \& Barak, 1991; Zillmann \& Bryant, 1988). These scenes usually depict the male in a

strong dominant position with the female in a submissive role in which she experiences sexual pleasure despite being in a humiliating position (Linz, Donnerstein, \& Penrod, 1987). Physical aggression is highly prevalent in pornographic scenes, which could be a potential explanation as to why physical aggression influences rape-myth acceptance, and why men exhibit higher levels of physical aggression and rape-myth acceptance compared to women. Research needs to be conducted to investigate pornography use and aggression, as this would have implications for policy (Seto \& Barbaree, 1995).

This study has several limitations. Firstly, due to the sensitivity of the topic area, 
participants may have answered the questions with the aim of appearing socially desirable (Maxfield \& Babbie, 2008). This limitation was addressed by collecting data online and anonymously. In addition, although there are issues with self-report data, evidence has suggested that anti-social behaviour can be accurately assessed with self-report measures (Woods, Hermann, Nunes, McPhail, \& Sewell, 2011). Secondly, the sample size is small and cultural attitudes are not taken into account. Thirdly, due to the correlational design of the study, causality cannot be established.

\section{Conclusion}

This study provides a modest step in sup- porting the association between physical aggressiveness and rape-myth acceptance. Identifying and understanding variables that influence the level of rape-myth acceptance amongst university students is important. Changing and/or eradicating rape myths may lead to individuals being less likely to engage in and be accepting of sexually aggressive behaviour (Lanier, 2001). This may in turn lead to victims being more willing to report sexual crimes. This study furthers our understanding of the factors which predict rape-myth acceptance and adds to the limited research conducted on the correlation between aggression and rape-myth acceptance.

\section{References}

Groth, A.N. (1979). Men who rape. The psychology of the offender. New York: Plenum Press

Grubb, A.R., \& Turner, E. (2012). Attribution of blame in rape cases: A review of the impact of rape myth acceptance, gender role conformity and substance use on victim blaming. Aggression 
and Violent Behavior, 17(5), 443 452. Harris, J.A. (1997). A further evaluation of the aggression questionnaire: Issues of validity and reliability. Behaviour Resolution Therapy, 35(11), 10471053.

Holcomb, D. R., Holcomb, L. C., Sondag, K. A., \& Williams, N. (1988). Attitudes about date rape: Gender differences among college students. College Student Journal, 25, 434439.

Kolivas, E. D., \& Gross, A. M. (2007). Assessing sexual aggression: Addressing the gap between rape victimization and perpetration prevalence rates. Aggression and Violent Behavior, 12, 315 328.

Koralewski, M., \& Conger, J. (1992). The assessment of social skills among sexually coercive males. Journal of Sex Research, 29(2), 169188.

Koss, M.P., \& Dinero, T.E. (1988). Predictors of sexual aggression among a national sample of male college students. Annals of the New York Academy of Sciences, 528(1), 133147.

Koss, M.P., \& Gidycz, C.A. (1985). The sexual experiences survey: Reliability and validity. Journal of Consulting and Clinical Psychology, 53(3), 442443.

L'Armand, K., \& Pepitone, A. (1982) Judgments of rape: A study of victim-rapist relationship and victim sexual history. Personality and Social Psychology Bulletin, 8(1), 134139.

Lalumiere, M., Harris, G., Quinsey, V., \& Rice, M. (2005). The causes of rape: Understanding individual differences in male propensity for sexual aggression. Washington, DC: American Psychological Association.

Lanier, C.A. (2001). Rape-accepting attitudes: Pre- cursors to or consequences of forced sex. Violence Against Women, 7(8), 876885. 
Linz, D., Donnerstein, E., \& Penrod, S. (1987). The findings and recommendations of the attorney general's commission on pornography: Do the psychological 'facts' fit the political fury? American Psychologist, 42, 946953.

Lonsway, K. A., \& Fitzgerald, L. F. (1994). Rape myths: In review. Psychology of Women Quarterly, 18, 133164.

Luginbuhl, J., \& Mullin, C. (1981). Rape and responsibility: How and how much is the victim blamed? Sex Roles, 7(5), 547559

Baugher, S. N., Elhai, J. D., Monroe, J. R., \& Gray, M. J (2010). Rape myth acceptance, sexual trauma history, and posttraumatic stress disorder. Journal of Interpersonal Violence, 25(11), 2036 2053.

Beck, V. S., Boys, S., Rose, C., \& Beck, E. (2012). Violence against women in video games: A prequel or sequel to rape myth acceptance? Journal of Interpersonal Violence, 27(15), 30163031.

Bohner, G., Reinhard, M., Rutz, S., Strum, S., Ker- schaum, B., \& Effler, D. (1998). Rape myths as neutralizing cognitions: Evidence for a causal impact of anti-victim attitudes on men's selfreported likelihood of raping. European Journal of Social Psychology, 28, 257268.

Burgess, G. H. (2007). Assessment of rape-supportive attitudes and beliefs in college men development, reliability, and validity of the rape attitudes and beliefs scale. Journal of Interpersonal Violence, 22(8), 973993.

Buss, A. H., \& Perry, M. P. (1992). The aggression questionnaire. Journal of Personality and Social Psychology, 63(3), 452459. 
Carmody, D.C., \& Washington, L.M. (2001). Rape myth acceptance among college women: The impact of race and prior victimization. Journal of Interpersonal Violence, 16(5), 424436

Edmonds, E. M., \& Cahoon, D. D. (1986). Attitudes concerning crimes related to clothing worn by female victims. Bulletin of the Psychonomic Society, 24(6), 444446.

Ellis, L. (1989). Theories of rape: inquiries into the causes of sexual aggression. New York: Hemisphere Publishing Company.

Field, H. (1978). Attitudes toward rape: A comparative analysis of police, rapists, crisis counsellors and citizens. Journal of Personality and Social Psychology, 36, 156179.

Fisher, W. A., \& Barak, A. (1991). Pornography, erotica, and behavior: More questions than answers. International Journal of Law and Psychiatry, 14, 6583.

Flood, M., \& Pease, B. (2009). Factors influencing attitudes to violence against women. Trauma Violence Abuse, 10, 125142.

Gidycz, C. A., Warkentin, J. B., \& Orchowski, L. M. (2007). Predictors of perpetration of verbal, physical, and sexual violence: A prospective analysis of college men. Psychology of Men \& Masculinity, 8, 79 94. doi:10.1037/1524- 9220.8.2.79

Malamuth, N. M. (1981). Rape proclivity among males. Journal of Social Issues, 37(4), 138157.

Maxfield, M. G., \& Babbie, E. (2008). Research methods for criminal justice and criminology. Belmont, CA: Thomas/Wadsworth.

Nunes, K. L., Hermann, C. A., \& Ratcliffe, K. (2013). Implicit and explicit attitudes toward rape 
are associated with sexual aggression. Journal of Interpersonal Violence, 28(13), 26572675.

Office for National Statistics Bulletin. (2013). An overview of sexual offending in England and Wales. Retrieved from https://www.gov.uk/ government/uploads/system/uploads/attachment _data/file/214970/sexual-offending-overview-jan -2013.pdf

Paul, L., Gray, M., Elhai, J., \& Davis, J. (2009). Perceptions of peer rape myth acceptance and disclosure in a sample of college sexual assault survivors. Psychological Trauma: Theory, Research, Practice and Policy, 1(3), 231241.

Payne, D. L., Lonsway, K. A., \& Fitzgerald, L. F. (1999). Rape myth acceptance: Exploration of its structure and its measurement using the Illinois rape myth acceptance scale. Journal of Research in Personality, 33(1), 2768.

Reddington, F. P., \& Kreisel, B. W. (2005). Sexual assault: The victims, the perpetrators, and the criminal justice system. Durham, N.C: Carolina Academic Press.

Richardson, D., \& Campbell, J. L. (1982). Alcohol and rape: The effect of alcohol on attributions of blame for rape. Personality and Social Psychology Bulletin, 8(3), 468476.

Scully, D. (1990). Understanding sexual violence: A study of convicted rapists. Boston: Unwin Hyman.

Scroggs, J. R. (1976). Penalties for rape as a function of victim provocativeness, damage and resistance. Journal of Applied Social Psychology, 6(4), 360368.

Schwartz, M.D, \& Leggett, M.S. (1999). Bad dates or emotional trauma? The aftermath of campus sexual assault. Violence Against Women, 5(3), 251271. 
Seto, M. C., \& Barbaree, H. E. (1995). The role of alcohol in sexual aggression. Clinical Psychology Review, 15, 545566.

Stahl, T., Eek, D., \& Kazemi, A. (2010). Rape victim blaming as system justification: The role of gender and activation of complementary stereotypes. Social Justice Research, 23(4), 239258.

Suarez, E., \& Gadalla. (2010). Stop blaming the victim: A meta-analysis on rape myths. Journal of Interpersonal Violence, 25(11), 126.

Tieger, T. (1981). Self-reported likelihood of rap- ing and the social perception of rape. Journal of Research in Personality, 15, 147158.

Valdivia-Peralta, M., Fonseca-Pedrero, E., Gonz alez-Bravo, L., \& Lemos-Gir aldez, S. (2014). Psychometric properties of the AQ aggression scale in Chilean students. Psico- thema, 26(1), 39 46.

Van Wie, V. E., Gross, A., \& Marx, B. P. (1995). Females' perception of date rape: An examination of two contextual variables. Violence Against Women, 1(4), 351366.

Walker, J., Archer, J., \& Davies, M. (2005). Effects of rape on male survivors: A descriptive analysis. Archives of Sexual Behaviour, 34(1), 6980.

White, B. H., \& Kurpius, S.E.R. (1999). Attitudes toward rape victims, effects of gender and professional status. Journal of Interpersonal Violence, 14(9), 989995.

Wilson, L., Mouilso, E., Gentile, B., Calhoun, K., \& Zeichner, A. (2015). How is sexual aggression related to nonsexual aggression? A meta- analytic review. Aggression and Violent Behavior, 24, 199213. 
Wright, P. J., \& Randall, A. K. (2012). Internet pornography exposure and risky sexual behaviour among adult males in the United Stated. Computers in Human Behavior, 28, 14101416.

Woods, M., Hermann, C. A., Nunes, K. L., McPhail, I. V., \& Sewell, R. (2011). The validity of self-reported risk among sex offenders. Poster presented at the 2nd North American Correctional and Criminal Justice Psychology Conference, Toronto, Ontario, Canada.

Zillmann, D., \& Bryant, J. (1988). Pornography’s impact on sexual satisfaction. Journal of Applied Social Psychology, 18, 438453. 